\title{
PENGARUH ROTASI KERJA, MOTIVASI KERJA DAN SEMANGAT KERJA TERHADAP KINERJA PEGAWAI KOMISI INDEPENDEN PEMILIHAN (KIP) ACEH
}

\author{
Saifuddin $^{1)}$ dan Kamaruddin ${ }^{2 *}$ \\ 1 Sekretaris KIP Kabupaten Bireuen \\ 2, Dosen FE Universitas Islam kebangsaan Indonesia (UNIKI) \\ *) email: kamal@uniki.ac.id
}

DOI:

https://doi.org/10.55178/idm.v2i4.220

ABSTRACT

Article history

Received:

September 11, 2021

Revised:

September 16, 2021

Accepted:

September 20, 2021

Page:

$28-36$

\section{Kata kunci}

Work Rotation,

Work Motivation,

Work Spirit, Employee

Performance
The purpose of this study is to prove and analyze, 1). The effect of job rotation on employee performance, 2) The effect of work motivation on employee performance, 3) The influence of employee morale on employee performance, and 4). Effect of job rotation, work motivation. and Simultaneous morale on the performance of Aceh KIP employees. The analysis was carried out descriptively and with a Path Analysis approach. The results of this descriptive study showed that the response of KIP Aceh employees who were examined regarding work rotation, found that the implementation of work rotation that could make high employee performance was only achieved by 59.67\%. Likewise, regarding employee work motivation, both with the support of employee needs, as well as the achievement of motivation expected by employees in the Aceh KIP environment only reached $68.82 \%$ which is classified as good. And the work spirit of Aceh KIP employees, the achievements tend to be good reaching $71.07 \%$. The results of the path analysis prove that 1) there is a significant effect on employee performance by $16.67 \%, 2)$ there is a significant influence on work motivation on the performance of Aceh KIP employees, which is 11.94\%. 3) There is a significant effect of work morale on the performance of Aceh KIP employees, amounting to $23.45 \%$. and 4). There is a simultaneous influence of work rotation, work motivation and work spirit on the performance of Aceh KIP employees by $52.8 \%$. While the remaining $47.2 \%$ not researched, such as work facilities, compensation, career development, education, and others.

\section{Pendahuluan (Introduction)}

Rotasi pekerjaan pada pegawai, di satu sisi suatu hal yang biasa, namun juga di sisi lain suatu hal yang tabu dan dipaksakan. Alasan positif dipandang rotasi untuk penyegaran pekerjaan pada pegawai, agar tidak bosan pada suatu tempat saja secara kontinu, dan agar pegawai diberi amanah pada tantangan lain dalam pekerjaan mereka.

Tidak terkecuali yang dilakukan pada Komisi Independen Pemilihan (KIP) Provinsi Aceh dalam menjalankan visinya yakni penyelenggara Pemilu yang memiliki integritas, profesional, mandiri, transparan dan akuntabel, demi terciptanya demokrasi Indonesia yang berkualitas. Juga melakukan beberapa rotasi jabatan dan pekerjaan, agar dapat sesuai dengan kemampuan, menciptakan keselarasan dan meningkatkan efektivitas kerja, sehingga pada ujungnya mampu para pegawai berkinerja baik.

Sebagaimana dinyatakan oleh Dessler (2003) dan Simamora (2004), bahwa dengan adanya rotasi pegawai agar bermanfaat bagi pegawai dan organisasi, karena akan berkesempatan untuk meningkatkan wawasan, pengalaman, pengetahuan, dan keahliannya dalam pekerjaan baru dan jabatan yang yang diamanahkan. Disamping itu, hal ini sebagai upaya mengatasi kebosonan pada pekerjaan yang telah dilakukan untuk waktu yang cukup lama. Juga, bagi institusi hal ini dijadikan sebagai tindakan pencegahan dan pengawasan adanya kemungkinan terjadi penyimpangan dalam pekerjaan atau jabatan dari pegawainya. 
Bagaimanapun manajemen kerja dan penempatan pegawai diatur sedimikian baik, namun factor motivasi kerja menjadikan suatu keniscayaan yang harus ada pada diri pegawai dan juga dorongan motivasi dari pimpinan agar kinerja pegawai dan kinerja institusi baik. Karena motivasi kerja adalah pemberian daya penggerak (baik internal ataupun eksternal) yang menciptakan minat dan kegairahan kerja seseorang agar mereka mau bekerja sama, bekerja efektif, dan terintegrasi dengan segala daya upayanya untuk mencapai kepuasan. (Hasibuan, 2007:143, Hakim, Baskoro dan Susanty, 2012).

Motivasi kerja pada diri pekerja bisa terjadi, manakala dipenuhi segala kebutuhannya. Oleh karenanya, organisasi melalui pimpinannya harus memperhatikan kebutuhan pegawai secara arif dan kebijaksana juga secara proporsional dengan beban kerja dan jabatan yang diberikan kepada pegawai.

Selain rotasi dan motivasi, secara substansi yang juga diharapkan bagi pegawai, adanya semangat berprestasi dan gigih dalam memaksimalkan kinerja. Hal ini juga harapan besar dalam institusi seperti Komisi Independen Pemilihan (KIP) Aceh, yang memang diberikan amanah oleh Negara untuk berbuat yang terbaik agar demokrasi dalam Negara Indonesia dapat terwujud sesuai undang-undang.

Semangat kerja diyakini akan regres dengan proses kerja, sehingga tujuan organisasi dapat tercapai sesuai rencana, sesuai dinyatakan Hasibuan (2008:94), bahwa semangat kerja adalah keinginan dan kesungguhan serta kedisiplinan seseorang bekerja untuk mencapai prestasi kerja yang maksimal. Hal ini dapat dilihat dari sikap moral kerja, kedisiplinan dan prestasi kerja. Maka dari itu, manajemen berfungsi untuk selalu mengukur hal ini, yang dikaitkan dengan perubahan kerja setiap pegawai. Juga mencari alasan jika terjadi penurunan semangat kerja, apakah disebabkan oleh gaji akibat sistem pengupahan, kondisi kerja, proses komunikasi.

Pengamtan awal peneliti pada KIP Aceh, sebagian pegawai masih belum optimal pencapaian kinerja yang diharapkan. Adanya dugaan peneliti, hal ini ada kaitannya dengan ketiga faktor yang diungkapkan diatas, yakni perlunya dilakukan rotasi, terus dipacu motivasi kerja dan semangat kerja pegawai. Sehingga KIP Aceh akan memiliki kewibawaan dalam mengemban amanah demokrasi.

\section{Tinjauan Literatur (Literature Review)}

\section{Hubungan Rotasi, Motivasi dan Semangat kerja}

Rotasi merupakan salah satu cara untuk menempatkan pegawai, dan upaya manajemen organisasi agar pegawai tidak merasa bosan dalam bekerja, sehingga perlu adanya tantangan pekerjaan, dan atau promosi pekerjaan yang lebih berkualitas bagi pegawai sesuai harapannya, dengan harapan akan mampu meningkatkan motivasi kerja pegawai. Perlakuan rotasi yang sesuai berdampak positif terhadap motivasi pegawai dalam bekerja dan pada akhirnya dapat meningkat kinerjanya (Faozen, 2019, Raja Saul Marto Hendry (2017).

Motivasi kerja pegawai, suatu keniscayaan bagi kepentingan tim kerja dan organisasi. Bagi tim kerja, dengan motivasi kerja pegawai yang tinggi berimbas dalam semangat kerja tim dalam menyelesaikan semua aktivitas di kantor atau institusi. Apalagi dalam institusi KIP memang bekerja secara tim.

Tanda seseorang memiliki motivasi sehingga muncul aura semangat dalam bekerja dapat dilihat dengan suasana kerja pegawai yang senang, bahagia, sehat dan disiplin dalam bekerja. Kurangnya motivasi pegawai dapat berdampak hasil kerja, semangat dalam menyelesaikan pekerjaan, banyaknya pekerjaan tertunda, dan kurangnya keterlibatan pegawai dalam pekerjaan. Hal ini dibuktikan oleh hasil riset Ashari, et al. (2018).

Maka pelaksana rotasi kerja pada pegawai harus tepat dan pekerjaan yang sesuai agar semangat dan produktivitas kerja karyawan dapat meningkat (Hasibuan, 2013), dan dapat mengurasi rasa bosan pegawai pada pekerjaan yang menahun (Robbins \& Judge, 2015:117).

\section{Pengaruh Rotasi Kerja terhadap Kinerja}

Rotasi yang dilakukan kepada pegawai yang tepat dan seuai memberikan kepuasan kerja dan meningkatkan produktifitas kerja serta kinerja pegawai. Rotasi ini juga suatu strtaegi untuk mengembangkan pegawai dalam hal keterampilan hasrat untuk bersinergi pada poensinya yang akhirnya berpengaruh terhadap kinerja. Hal ini ditemukan oleh Santoso (2017) yang melakukan penelitian pada Balai Pendidikan dan Pelatihan Transportasi Darat Palembang.

Hal senada juga ditemukan Manopo, dkk (2018) bahwa tindakan rotasi terhadap pegawai berpengaruh signifikan terhadap kinerja karyawan. Penerapan rotasi kerja pada waktu yang tepat dan sasaran yang benar, akan lebih efektif dalam meningkatkan kinerja karyawan. 


\section{Pengaruh Motivasi Kerja terhadap Kinerja}

Aspek motivasi kerja mutlak mendapat perhatian serius dari para pimpinan organisasi, karena hal ini penting dalam meningkatkan kinerja pegawai (Siagian, 2002). Karena pendapat Munandar (2001) bahwa karyawan yang mempunyai motivasi kerja yang tinggi cenderung mempunyai kinerja tinggi. Dan hal ini dibuktikan dari penelitian Cion Orocomna, dkk (2018) terhadap Karyawan PT. TASPEN (Persero) Cabang Manado menunjukkan bahwa motivasi kerja berpengaruh positif dan signifikans sebesar 21,3\%.

\section{Pengaruh Semangat Kerja terhadap Kinerja}

Prestasi kerja yang maksimal yang akan terukur dari kinerja, tentu tidak tercipta dengan sendirinya. Pengalaman, kemampuan dan semangat kerja pegawai memberi andil terhadap hal itu. Semangat kerja ini akan merangsang seseorang untuk berkarya dan berkreativitas dalam pekerjaannya (Hasibuan, 2003:94). Maknanya dengan semangat kerja yang tinggi maka kinerja karyawan akan dapat bekerja sama dengan individu lainnya secara maksimal sehingga pekerjaan lebih cepat, kesalahan dan absensi dapat diperkecil, dan hasil kerja optimal.

Penelitian Syahropi dan Kasmiruddin (2016) pada Karyawan PT. Bangkinang Pekanbaru diperoleh bahwa semangat kerja yang diukur melalui tingkat absensi, kepuasan kerja, kerja sama dan kedisiplinan cukup berdampak positif pada kinerja karyawan.

\section{Metode Penelitian (Methodology)}

\section{a. Metode dan Variabel Penelitian}

Penelitian ini dilakukan terhadap pegawai KIP Aceh, yang terdiri 70 pegawai berstatus PNS dan pegawai organik (lingkungan Komisi Pemilihan Umum - KPU) dan selebihnya diperbantukan dari Pemerintah Aceh. Melalui penelitian asosiatif dengan pendekatan kuantitatif, sehingga mampu menjelaskan hubungan kausal dan pengaruh antara variabel bebas (Rotasi, Motivasi, dan Semangat kerja), terhadap variabel dependent yakni Kinerja Pegawai (Y), dengan langkah uji hipotesis secara statistik. Adapun variabel, dimensi dan indikator pengukurnya dinyatakan berikut ini.

Tabel 1. Operasional Variabel Penelitian

\begin{tabular}{|c|c|}
\hline Variabel & Indikator \\
\hline $\begin{array}{c}\text { Rotasi kerja } \\
\left(\mathrm{X}_{1}\right)\end{array}$ & $\begin{array}{l}\text { - Kemampuan kerja } \\
\text { - Sikap kerja } \\
\text { - Kondisi kerja } \\
\text { - Sikap pribadi }\end{array}$ \\
\hline $\begin{array}{c}\text { Motivasi kerja } \\
\text { (X2) } \\
\text { Sumber: Hasibuan (2011:141) }\end{array}$ & $\begin{array}{l}\text { - Kebutuhan akan prestasi } \\
\text { - Kebutuhan akan afiliasi } \\
\text { - Kebutuhan akan kekuasaan }\end{array}$ \\
\hline $\begin{array}{c}\text { Semangat kerja } \\
(\mathrm{X} 3) \\
\text { Sumber: Tohardi }(2011: 82)\end{array}$ & $\begin{array}{l}\text { - Naiknya Produktivitas karyawan } \\
\text { - Tingkat absensi rendah } \\
\text { - Labour Turn Over } \\
\text { - Berkurangnya kegelisahaan }\end{array}$ \\
\hline $\begin{array}{l}\text { Kinerja } \\
\text { (Y) }\end{array}$ & $\begin{array}{l}\text { - Kuantitas } \\
\text { - Kualitas } \\
\text { - Waktu } \\
\text { - Biaya }\end{array}$ \\
\hline
\end{tabular}

\section{b. Alat Analisis}

Alat analisis masalah dan menjawab tujuan penelitian, dilakukan secara analisis deskriptif dan analisis dengan model analisis jalur, karena antar variabel bebas adanya hubungan kausalitas. Sehingga dapat menganalisis secara direct maupun undirect variable eksogenues terhadap variable endogenues (Marwan Hamid, dkk; 2019:10).

Untuk dapat menggunakan alat analisis ini, dipastikan data memiliki skala ukur minimal interval. Juga syarat statistik regresi dan analisis jalur, terpenuhinya semua asumsi klasik, yakni normalitas, heterosidasitas, multikolinieritas. 


\section{Hasil dan Pembahasan (Results and Discussion)}

\section{a. Karakteristik Responden}

Berdasarkan informasi data 70 pegawai Komisi Pemilihan Umum (KIP) Aceh, maka diperoleh informasi karakteristiknya sebagai berikut:

Tabel 2. Karakteristik Responden Penelitian

\begin{tabular}{|l|l|l|c|}
\hline No & Karaketristik & \multicolumn{1}{|c|}{ Kategori } & Persentase \\
\hline \multirow{2}{*}{1} & \multirow{2}{*}{ Jenis Kelamin } & Laki-laki & 68.57 \\
\cline { 3 - 4 } & & Perempuan & 31.43 \\
\hline \multirow{2}{*}{3} & \multirow{2}{*}{ Status Kawin } & Belum Menikah & 10.00 \\
\cline { 3 - 4 } & \multirow{2}{*}{ Usia } & Sudah Menikah & 88.57 \\
\cline { 3 - 4 } & & $\leq .30 \mathrm{Th}$ & 8.57 \\
\cline { 3 - 4 } & & $31-40 \mathrm{Th}$ & 61.43 \\
\cline { 3 - 4 } & & $41-50 \mathrm{Th}$ & 27.14 \\
\cline { 3 - 4 } & & $>.50 \mathrm{Th}$ & 2.86 \\
\hline \multirow{3}{*}{} & \multirow{2}{*}{ Pendidikan } & SMA & 21.42 \\
\cline { 3 - 4 } & & Diploma & 64.29 \\
\cline { 3 - 4 } & & S1/S2 & 64.29 \\
\hline
\end{tabular}

Sumber: Hasil Penelitian 2021

Umumnya pegawai KIP yang diteliti adalah laki-laki $(68,57 \%)$ dengan status sudah meninkah $(88,57 \%)$, dengan usia di dominasi antara 31 - 40 tahun. Latar belekang pendidikan cukup baik, yakni setengahnya adalah Sarjana dan terdapat $14,29 \%$ yang lulusan S2.

\section{b. Pemeriksaan Validitas Butir Pernyataan dalam Instrumen Penelitian}

\section{Uji Validitas Instrumen Rotasi Kerja}

Sesuai dengan konsep operasional penelitian ini, Instrumen yang mengukur variabel Rotasi kerja $\left(\mathrm{X}_{1}\right)$ berdasarkan 4 indikator yakni 1) Kemampuan kerja, 2) Sikap kerja, 3) Kondisi kerja dan 4) Sikap pribadi pegawai. Hasil uji validitas atas instrument pengumpulan data variable ini dinyatakan berikut:

Tabel 3. Uji Validitas Instrumen untuk Variabel Rotasi kerja

\begin{tabular}{|c|l|c|c|c|}
\hline Butir & \multicolumn{1}{|c|}{ Pernyataan } & r-hitung & r-tabel & Keputusan \\
\hline 1 & Pengetahuan & 0.479 & 0,235 & Valid \\
\hline 2 & Keterampilan & 0.525 & 0,235 & Valid \\
\hline 3 & Penguasaan pekerjaan & 0.518 & 0,235 & Valid \\
\hline 4 & Kerjasama & 0.548 & 0,235 & Valid \\
\hline 5 & Ada/tidak ada perubahan & 0.438 & 0,235 & Valid \\
\hline 6 & Sikap terhadap pekerjaan & 0.623 & 0,235 & Valid \\
\hline 7 & Minat terhadap pekerjaan & 0.440 & 0,235 & Valid \\
\hline
\end{tabular}

Sumber: Hasil Olahan SPSS

Dari hasil perhitungan validitas semua item pernyataan yang mengkur variabel Rotasi kerja (X1), semua butir pernyataan yang dinyatakan valid, sehingga dapat digunakan dalam penelitian selanjutnya.

\section{Uji Validitas Instrumen Motivasi kerja}

Menggunakan konsep Pandji Anoraga (2012). Instrumen yang mengukur variabel Motivasi kerja berdasarkan indikator pengukur (Tabel 1). Maka diperoleh koefisien korelasi dalam membuktikan validitas semua item yang mengukur variabel terdiri atas 8 item, seperti pada tabel 4 berikut:

Tabel 4. Uji Validitas Instrumen untuk Variabel Motivasi kerja

\begin{tabular}{|c|l|c|c|c|}
\hline Butir & Pernyataan & r-hitung & r-tabel & Keputusan \\
\hline 1 & Mengembangkan kreativitas & 0.511 & 0,235 & Valid \\
\hline 2 & Antusias untuk berprestasi tinggi & 0.658 & 0,235 & Valid \\
\hline 3 & Kebutuhan akan diterima oleh orang lain & 0.552 & 0,235 & Valid \\
\hline 4 & Kebutuhan akan perasaan dihormati & 0.689 & 0,235 & Valid \\
\hline 5 & Kebutuhan akan perasaan maju dan tidak gaagal & 0.542 & 0,235 & Valid \\
\hline 6 & Kebutuhan akan perasaan ikut serta & 0.720 & 0,235 & Valid \\
\hline 7 & Memiliki kedudukan yang terbaik & 0.495 & 0,235 & Valid \\
\hline 8 & Mengerahkan kemampuan untuk mengerahkan kekuasaan & 0.598 & 0,235 & Valid \\
\hline
\end{tabular}


Dari hasil perhitungan validitas variabel motivasi kerja, terbukti bahwa semua item yang dunyatakan valid, dan dianggap sudah mewakili variabel ini.

\section{Uji Validitas Instrumen Semangat Kerja}

Menggunakan konsep Tohardi (2011:82). Instrumen yang mengukur variabel semangat kerja dirancang dari 4 dimensi lihat tabel 1). Dari dimensi tersebut, dikembangkan 8 item pernyataan yang akan di uji validitasnya, yakni:

Tabel 5. Uji Validitas Instrumen untuk Variabel Semangat kerja

\begin{tabular}{|c|l|c|c|c|}
\hline Butir & \multicolumn{1}{|c|}{ Pernyataan } & r-hitung & r-tabel & Keputusan \\
\hline 1 & Jalinan kerjasama dengan teman sekerja dan pimpinan & 0.497 & 0,235 & Valid \\
\hline 2 & $\begin{array}{l}\text { Menyelesaikan pekerjaan sesuai dengan kemampuan yang } \\
\text { dimiliki }\end{array}$ & 0.584 & 0,235 & Valid \\
\hline 3 & Menyelesaikan tugas dengan cepat & 0.412 & 0,235 & Valid \\
\hline 4 & Dukungan Lingkungan kerja yang baik & 0.607 & 0,235 & Valid \\
\hline 5 & Menganggap rekan kerja saya sebagai keluarga & 0.711 & 0,235 & Valid \\
\hline 6 & $\begin{array}{l}\text { Pegawai menjalin hubungan yang baik dengan teman } \\
\text { sekerja baik didalam pekerjaan maupun diluar pekerjaan }\end{array}$ & 0.694 & 0,235 & Valid \\
\hline 7 & Waktu kerja sesuai yang telah ditentukan & 0.663 & 0,235 & Valid \\
\hline 8 & Masuk kerja tepat pada waktunya & 0.398 & 0,235 & Valid \\
\hline
\end{tabular}

Sumber: Hasil olahan SPSS

Hasil tabel diatas, maka semua item dapat digunakan untuk penelitian selanjutnya.

\section{Uji Validitas Instrumen Kinerja}

Instrumen yang mengukur variabel kinerja berdasarkan dimensi kuantitas, kualitas, kebutuhan waktu kerja dan penggunaan biaya. Validasi item angket variabel kinerja dengan jumlah 8 butir pernyataan pengukur variabel ini, dengan hasil uji berikut:

Tabel 6. Uji Validitas Instrumen untuk Variabel Kinerja

\begin{tabular}{|c|l|c|c|c|}
\hline Butir & Pernyataan & r-hitung & r-tabel & Keputusan \\
\hline 1 & Menghasilkan output yang berkualitas sesuai standart & 0.637 & 0,235 & Valid \\
\hline 2 & $\begin{array}{l}\text { Bekerja dengan serius sehingga mampu menyelesaikan } \\
\text { pekerjaan dengan rapi dan teliti }\end{array}$ & 0.654 & 0,235 & Valid \\
\hline 3 & Hasil kerja sesuai dengan target yang dibebankan instansi & 0.676 & 0,235 & Valid \\
\hline 4 & Hasil pekerjaan terus meningkat dari waktu ke waktu & 0.457 & 0,235 & Valid \\
\hline 5 & Pegawai disiplin datang tepat waktu & 0.790 & 0,235 & Valid \\
\hline 6 & Tugas yang diberikan selalu selesaikan dengan tepat waktu & 0.725 & 0,235 & Valid \\
\hline 7 & Menyelesaikan tugas tambahan dengan tepat waktu & 0.565 & 0,235 & Valid \\
\hline 8 & Bekerja sesuai dengan fungsi dalam instansi & 0.647 & 0,235 & Valid \\
\hline
\end{tabular}

Sumber: Hasil olahan SPSS

Dari hasil diatas, semua butir pernyataan dapat digunakan untuk penelitian selanjutnya.

\section{c. Hasil analisis Deskriptif}

Berdasarkan hasil kuesioner yang telah teruji validitas dan reliabilitasnya diperoleh informasi sebagai berikut.

Tabel 7. Deskripsi Penilaian Pegawai tentang Variabel Penelitian

\begin{tabular}{|l|c|c|c|c|c|c|}
\hline \multirow{2}{*}{ Variabel } & \multicolumn{5}{|c|}{ Jumlah \& } & \multirow{2}{*}{$\begin{array}{c}\text { Skor } \\
\text { Persentase } \\
\text { Pencapaian }\end{array}$} \\
\cline { 2 - 8 } & STS & TS & KS & S & SS & Perstase Jawaban Responden \\
\hline \multirow{2}{*}{ - Rotasi kerja : 7 pernyataan } & 37 & 114 & 173 & 152 & 14 & \multirow{2}{*}{59,67} \\
\cline { 2 - 8 } & 7.55 & 23.27 & 35.31 & 31.02 & 2.86 & \\
\hline \multirow{2}{*}{ - Motivasi kerja : 8 pernyataan } & 1 & 30 & 282 & 215 & 32 & \multirow{2}{*}{68,82} \\
\cline { 2 - 8 } & 0.18 & 5.36 & 50.36 & 38.39 & 5.71 & \\
\hline \multirow{2}{*}{ - Semangat kerja : 8 pernyataan } & 9 & 19 & 241 & 235 & 56 & \multirow{2}{*}{71,07} \\
\cline { 2 - 7 } & 1.61 & 3.39 & 43.04 & 41.96 & 10.00 & \\
\hline \multirow{2}{*}{ - Kinerja : 8 pernyataan } & 14 & 32 & 260 & 230 & 24 & \multirow{2}{*}{67,79} \\
\cline { 2 - 6 } & 2.50 & 5.71 & 46.43 & 41.07 & 4.29 & \\
\hline
\end{tabular}

Sumber : Hasil Peneltian, 2021 
Angket dirancang tertutup dengan 5 pilihan dari sangat setuju hingga sangat tidak setuju. Berdasarkan jawaban atau persepsi responden dari setiap variabel, maka dijelaskan berikut ini:

1) Terdapat 33,88\% responden menyatakan sangat setuju dan setuju bahwa rotasi kerja bermanfaat untuk meningkatkan kinerja pegawai. Pelaksanaan rotasi kerja yang dapat membuat kinerja baik dicapai sebesar $59,67 \%$.

2) Terdapat $44,10 \%$ responden menyatakan sangat setuju dan setuju bahwa motivasi kerja pegawai baik dengan dukungan kebutuhan pegawai, dan pencapaian motivasi yang diharapkan kepada pegawai baru sebesar $68,82 \%$ yang baik.

3) Terdapat $51,96 \%$ responden menyatakan sangat setuju dan setuju bahwa semangat kerja pegawai KIP Aceh telah dijalankan sesuai dengan diharapkan, khususnya dalam menjalin kerjasama, menyelesaikan kerja yang dibebankan dan disiplin dalam mengatur waktu kerja. Pencapaian semangat kerja di kalangan pegawai KIP Aceh cenderung baik mencapai $71,07 \%$.

4) Terdapat $45,36 \%$ responden menyatakan sangat setuju dan setuju bahwa kinerja pegawai KIP Aceh tinggi, namun besar juga yang menyatakan kurang yakni 46,43\%. Tingkat kinerja pegawai KIP Aceh baru mencapai $67,79 \%$ yang sesuai harapan dalam sistem kerja ditetapkan.

\section{d. Hasil Analisis Jalur}

Dengan pendekatan analisis jalur, yakni kombinasi regresi variabel bebas terhadap variabel tak bebas (Kinerja) dan adanya hubungan kausalitas antar variabel bebas $\left(\mathrm{r}_{\mathrm{xi}, \mathrm{xj}}\right)$, dinyatakan dalam gambar 1 berikut:

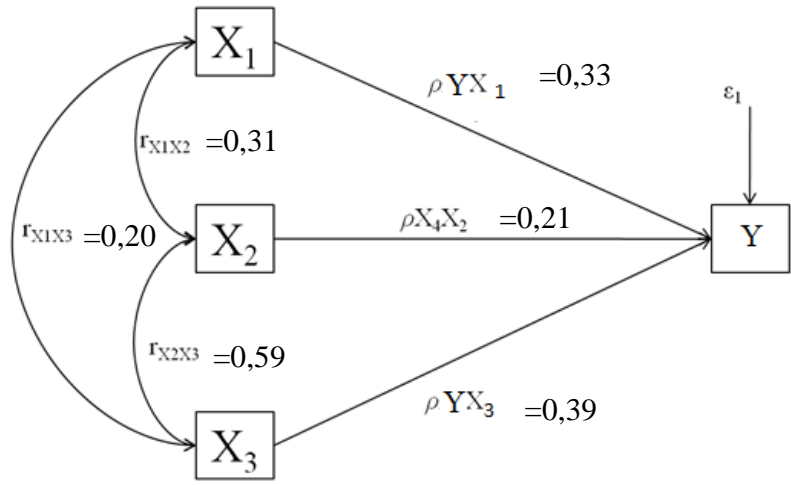

Gambar 1 Diagram Jalur Penelitian

\section{e. Uji Model}

Untuk dapat menyatakan bahwa hasil hitung koefisien korelasi $\left(\mathrm{r}_{\mathrm{xi}, \mathrm{xj}}\right)$ yang merupakan korelasi hubungan kausalitas antar variabel eksogen, dan signifikansi koefisien jalur yang merupakan koefisien pengaruh variabel eksogen terhadap endogen $(\mathrm{Y})$, dilakukan pengujiannya.

Hipotesis 1: Rotasi kerja berpengaruh terhadap Kinerja

Hasil perhitungan menunjukkan harga $t_{\text {hitung }}$ sebesar 3,804 yang lebih besar dari t-tabel $=2,00$, dan nilai ini signifikans pada taraf uji $0,000 \%$. Sehingga Ho ditolak dan Ha diterima artinya koefisien jalur variabel rotasi kerja berpengaruh terhadap Kinerja pegawai KIP Aceh.

\section{Hipotesis 2: Motivasi kerja berpengaruh terhadap Kinerja}

Diperoleh nilai $t_{\text {hitung }}$ sebesar 2,018. Dengan demikian $t_{\text {hitung }}>t_{\text {tabel }}(2,018>2,00)$, dan nilai ini juga signifikansi dari hasil olahan data pada taraf uji $0,048 \%$. Sehingga Ho ditolak dan Ha diterima artinya koefisien jalur variabel Motivasi kerja terhadap Kinerja, dapat dinyatakan signifikan pada taraf signifikan $\alpha=0,05$. Dengan demikian Motivasi kerja berpengaruh signifikans terhadap Kinerja pegawai KIP Aceh.

Hipotesis 3: Semangat kerja berpengaruh terhadap Kinerja

Diperoleh bahwa $t_{\text {hitung }}$ sebesar 3,781 Dengan demikian $t_{\text {hitung }}>t_{\text {tabel }}(3,781>2,00)$. Sehingga Ha diterima artinya koefisien jalur variabel Semangat kerja $\left(\mathrm{X}_{3}\right)$ berpengaruh berpengaruh terhadap Kinerja pegawai KIP Aceh. 


\section{f. Hasil Analisis Pengaruh variabel dan Pembahasan}

Dengan pendekatan analisis jalur atau path-analysis dapat dijabarkan adanya pengaruh langsung (direct) dan pengaruh tidak langsung (indirect). Pengaruh tidak langsung terjadi, karena adanya hubungan kausalitas antar variabel eksogen. Berikut dijabarkan hasilnya:

\section{1). Pengaruh Variabel Rotasi kerja terhadap Kinerja Pegawai}

\section{Pengaruh langsung:}

Besarnya pengaruh langsung Rotasi kerja terhadap Kinerja, dengan koefisien jalur $\left(\rho_{\mathrm{yx} 1}=0,339\right)$, Sehingga besarnya pengaruh langsung ini adalah: $11,49 \%$.

\section{Pengaruh Tidak langsung}

Besarnya pengaruh tak langsung Rotasi kerja terhadap Kinerja, yang di hitung sebagai berikut:

- Pengaruh Rotasi kerja melalui motivasi kerja terhadap Kinerja yakni : $(0,339)(0,318)(0,219) \times 100 \%=$ $2,36 \%$

- Pengaruh Rotasi kerja melalui semangat kerja terhadap Kinerja, yakni $(0,339)(0,209)(0,398)$ x $100 \%$ $=2,82 \%$

Pengaruh Total Rotasi kerja terhadap Kinerja Pegawai

Berdasarkan total rotasi kerja terhadap kinerja pegawai, yakni : 11,49\%+2,36\%+2,82\%=16,67\%

\section{2). Pengaruh Variabel Motivasi kerja terhadap Kinerja Pegawai}

\section{Pengaruh langsung:}

Besarnya pengaruh langsung Motivasi kerja terhadap Kinerja, dengan koefisien jalur $\left(\rho_{\mathrm{yx} 2}=0,219\right)$, Sehingga besarnya pengaruh langsung ini adalah 4,80\%.

\section{Pengaruh Tidak langsung}

Besarnya pengaruh tak langsung motivasi kerja terhadap Kinerja, yaitu:

- Pengaruh Motivasi kerja melalui Rotasi kerja terhadap Kinerja: $(0,219)(0,318)(0,339) \times 100 \%=2,36 \%$

- Pengaruh Rotasi kerja melalui semangat kerja terhadap Kinerja: $(0,219)(0,549)(0,398) \times 100 \%=4,79 \%$

\section{Pengaruh Total Motivasi kerja terhadap Kinerja Pegawai}

Berdasarkan pengaruh langsung dan tidak langsung, maka besarnya pengaruh total sebesar 4,80\%+ $2,36 \%+4,79 \%=11,94 \%$.

\section{3). Pengaruh Variabel Semangat kerja terhadap Kinerja Pegawai}

\section{Pengaruh langsung:}

Besarnya pengaruh langsung Semangat kerja terhadap Kinerja pegawai KIP Aceh, dengan koefisien jalur $\left(\rho_{\mathrm{yx} 3}=0,398\right)$, Sehingga besarnya pengaruh langsung ini adalah: $15,84 \%$.

\section{Pengaruh Tidak langsung}

Besarnya pengaruh tak langsung Semangat kerja terhadap Kinerja pegawai, yaitu:

- Pengaruh Semangat kerja melalui Rotasi kerja terhadap Kinerja dinyatakan sebagai : $(0,398)(0,209)(0,339) \times 100 \%=2,82 \%$

- Pengaruh Semangat kerja melalui Motivasi kerja terhadap Kinerja, dinyatakan sebagai: $(0,398)(0,549)(0,219) \times 100 \%=4,79 \%$

\section{Pengaruh Total Semangat kerja $\left(\mathbf{X}_{3}\right)$ terhadap Kinerja pegawai $(\mathbf{Y})$}

Berdasarkan pengaruh langsung dan tidak langsung, maka dapat dihitung besarnya pengaruh total Semangat kerja terhadap Kinerja , yakni : 15,84 \% +2,82 \% +4,79\%=23,45\%.

\section{4). Pengaruh Rotasi kerja, Motivasi kerja, dan Semangat kerja terhadap Kinerja Pegawai KIP Aceh}

Model variable dinyatakan dalam persamaan $Y=0,339 X_{1}+0,219 X_{2}+0,398 X_{3}$

( $\mathrm{Y}=$ Kinerja pegawai, $\mathrm{X}_{1}=$ Rotasi kerja, $\mathrm{X}_{2}=$ Motivasi kerja, $\mathrm{X}_{3}=$ Semangat kerja)

Maka dari persamaan tersebut dapat dijelaskan bahwa koefisien jalur Koefisien Rotasi kerja bernilai positif $(0,339)$ artinya apabila pelaksanaan rotasi kerja sesuai dengan kemampuan pegawai dan berjalan baik akan dapat mendukung kinerja pegawai KIP Aceh dengan rata-rata kenaikan 33,9\%. Juga adanya motivasi kerja mendukung kinerja pegawai dengan koefisien bernilai positif $(0,219)$ artinya rata-rata kenaikkan nya adalah $21,9 \%$. Koefisien jalur Semangat kerja bernilai positif $(0,398)$ artinya apabila tingkat semangat kerja meningkat akan menaikkan rata-rata 39,8 \% kinerja pegawai KIP Aceh. 
Kemudian, berdasarkan nilai determinasi $\left(\mathrm{R}^{2}\right)$ yakni 0,528 menjelaskan bahwa kontribusi faktor Rotasi kerja, motivasi kerja dan semangat kerja terhadap Kinerja pegawai KIP Aceh sebesar 52,8\%. Sementara sisanya dari peran variabel yang tidak diteliti sebesar $47,2 \%$.

\section{Simpulan (Conclusion)}

Berdasarkan analisis secara kuantitatif, menggunakan pendekatan analisis jalur, maka:

a) Terdapat Pengaruh yang signifikans baik pengaruh langsung faktor Rotasi kerja terhadap Kinerja Pegawai KIP Aceh $(Y)$, ataupun pengaruh tidak langsung karena adanya hubungan kausal Rotasi kerka, Motivasi dan semangat terhadap Kinerja pegawai KIP Aceh yang diteliti, yakni sebesar 16,67 \%.

b) Terdapat Pengaruh yang signifikans baik pengaruh langsung faktor Motivasi kerja, ataupun pengaruh tidak langsung karena adanya hubungan kausal Motivasi kerja dengan rotasi kerja dan semangat kerja terhadap Kinerja pegawai KIP Aceh, yakni 11,94\%.

c) Terdapat Pengaruh yang signifikans baik pengaruh langsung faktor Semangat kerja terhadap Kinerja pegawai KIP Aceh, ataupun pengaruh tidak langsung karena adanya hubungan kausal dengan Rotasi kerja dan motivasi kerja, yakni $23,45 \%$.

d) Terdapat Pengaruh secara simultan Rotasi kerja, Motivasi kerja dan Semangat kerja terhadap Kinerja pegawai KIP Aceh sebesar 52,8 \%. Sementara sisanya (nilai residu) dari peran variabel yang tidak diteliti sebesar $47,2 \%$. Nilai residu tersebut menujukkan bahwa terdapat faktor-faktor lain yang dapat mempengaruhi variabel Kinerja pegawai KIP Aceh, seperti fasilitas kerja, konpensasi, pengembangan karir, Pendidikan, dan lain-lain.

\section{DAFTAR PUSTAKA (References)}

1) Anoraga, Pandji, 2012, Manajemen Bisnis, Rineka Cipta, Jakarta.

2) A.S, Munandar. 2001, Psikologi Industri dan Organisasi. Jakarta : UI.

3) Ashari, et al., 2018, Pengaruh Motivasi Kerja terhadap Semangat Kerja pada Karyawan Primagama Cabang Rambipuji dan Ambalu, e-Sospol XXX

4) Bambang Wahyudi. 2002, Manajemen Sumber Daya Manusia, Edisi Pertama,. Penerbit SULITA, Bandung

5) Cion Orocomna, Tinneke M. Tumbel, Sandra I. Asaloei. 2018, Pengaruh Motivasi Kerja terhadap Kinerja Karyawan PT. TASPEN (Persero) Cabang Manado, Jurnal Administrasi Bisnis, Vol 7 No 1.

6) David T. Manopo, dkk. 2018, Pengaruh Rotasi Kerja, Etos Kerja Dan Karakteristik Kerja Terhadap Kinerja Karyawan Pada Pt.Jasaraharja Putera Cabang Manado, Jurnal EMBA Vol.6 No.4 September 2018, Hal. $2738-2747$

7) Dessler, Gary. 2008, Human Resources Management, New Jersey: A Simon \& Schuster Company.

8) Faozen. 2019, Dampak Rotasi Kerja Pada Motivasi dan Kinerja Karyawan Hotel di Jember, Jurnal Pariwisata Vol 2 Nomor 1 (2019).

9) Ferdinand. 2005. Metode Penelitian Manajemen. Edisi 2. BP Universitas. Diponogoro : Semarang

10) Ghozali, Imam, 2005. Aplikasi Analisis Multivariate dengan program SPSS.

11) Hasibuan, Malayu S.P 2007, Manajemen Sumber Daya Manusia Perusahaan,Bandung, PT. Bumi Aksa

12) Hasibuan,Malayu S. 2009, Manajemen Sumber Daya Manusia, edisi revisi, Jakarta, PT.Bumi Aksara.

13) Ishak Syahropi Dan Kasmiruddin. 2016, Pengaruh Semangat Kerja Terhadap Kinerja Karyawan PT. Bangkinang Di Pekanbaru, JOM FISIP Volume 3 No. 2 Oktober 2016

14) Kaswan. 2017. Psikologi Industri dan Organisasi. Bandung: Alfabeta.

15) Kaymaz. 2010. Pengaruh Rotasi Kerja, Stres, Kepuasan Kerja Dan Komitmen Organisasi Terhadap Kinerja Karyawan. Journal of Management, 1(4), 1-10. https://doi.org/10.3975/cagsb.2017.02.15

16) Marwan Hamid, Ibrahim Sufi, Win Konadi, dan Yusrizal Akmal, 2019. Analisis Jalur Dan Aplikasi SPSS v-25, Edisi Pertama, Medan: Sefa Bumi Persada.

17) McCarthy, K. 2013. Employee motivation survey 2013. Mazars. Retrieved March 8, 2015, from http://www.mazars.ie/Home/News/Publications/Surveys/External-Employee-MotivationSurveys/ Employee-Motivation-Survey-2013

18) Raja Saul Marto Hendry. 2017, Pengaruh Rotasi Kerja Dan Lingkungan Kerja Terhadap Semangat Kerja Pegawai Dinas Kesehatan Kabupaten Labuhanbatu Utara, Jurnal Informatika, Vol 5, No 1 (2017)

19) Robbin \& Judge. 2015. Perilaku Organisasi Edisi 16. Jakarta. Salemba Empat.:

20) Santoso. 2017. Pengaruh Rotasi Pegawai, Kepuasan Kerja dan Perilaku Kerja Terhadap Kinerja Pegawai Negeri Sipil Di Lingkungan Balai Pendidikan dan Pelatihan Transportasi Darat Palembang. 
21) Siagian, Sondang P., 2002, Manajemen Sumber Daya Manusia, Cetakan Kelima, Bumi Aksara. Jakarta.

22) Simamora, Henry. 2004. Manajemen Sumber Daya Manusia. Yogyakarta: STIE YKPN

23) Susanty, A., Baskoro, S. W. 2012. Pengaruh Motivasi Kerja Dan Gaya Kepemimpinan Terhadap Disiplin Kerja Serta Dampaknya Pada Kinerja Karyawan (Studi Kasus Pada PT. PLN (Persero) APD Semarang). Vol. 7 (2) :77-84

24) Stevens, Michael J \& Michael A, Champion. 1994. Journal of Management. The Knowledge, Skill, and Abillity Requirements for Teamwork: Implications for Human Resource Management. 20 (2): 503530

25) Tohardi, Ahmad. 2011. Pemahaman Praktis Manajemen Sumber Daya. Manusia, CV. Mandar Maju, Bandung. 